\title{
Knowing what to remember and forget: A developmental study of cue memory in intentional forgetting
}

\author{
ELYSE BRAUCH LEHMAN, RAY MORATH, KAREN FRANKLIN, and VERONIQUE ELBAZ \\ George Mason University, Fairfax, Virginia
}

\begin{abstract}
These experiments are the first to investigate children's encoding and use of information about a memory cue in Bjork's (1972) intentional forgetting task. In Experiment 1, children in Grades 2, 4, and 6 and college students were given cues to either remember or forget after the presentation of each picture. Recall and recognition tests of pictures and cues followed. The procedure in Experiment 2 was identical to that in Experiment 1 except that the list of presentation pictures was altered for some children (Grades 3 and 4) and adolescents (Grades 8 and 9) so that remember and forget cues were associated with particular taxonomic categories. In Experiment 3 , the testing component was modified so that children (Grades 2, 3, and 4) and college students were asked to recall only the cue associated with each picture. The results indicated that (1) children as young as second graders encode the cue associated with each picture, although to a lesser extent than do college students, (2) much improvement in intentional forgetting is still occurring during adolescence, (3) only adults adequately cluster their recall by cue, (4) associating remember and forget cues with items from different categories does not increase the differentiation between cues, and (5) eliminating picture recall and recognition has minimal effects on the magnitude of cue judgments. These results suggest that children's difficulties on intentional forgetting tasks stem, at least in part, from their poorer encoding of information about whether an item should be remembered or forgotten.
\end{abstract}

Keeping outdated material stored in memory from interfering with new information has been studied with the intentional forgetting paradigm developed by Bjork (1972). The paradigm may be viewed as a laboratory analogue to everyday memory updating situations, such as switching computer software, recalling where the car has been parked today, and learning a new telephone number when we move.

The key to Bjork's (1972) procedure is that after material has been presented for study, subjects are told to remember some of it and to forget the remainder. The remember and forget cues can be presented after each item (item cuing) or after a group of items (list cuing). If intentional forgetting is successful, there will be only a small number of intrusions of items cued "forget" (Fcued items) when subjects are asked to recall only the items cued "remember" (R-cued items) and poor recall of F-cued items when subjects are asked to recall all items.

This study was supported in part by a study leave and by Graduate Research Assistant Awards to the first author from George Mason University. Portions of the research were presented at the Conference on Human Development, Pittsburgh, April 1994. The authors wish to thank the following principals for their support: Sister Mary Reiling (St. Leo's School), Sister Marie Rene (St. Michael's School), The Reverend Robert G. Mulligan (Paul VI High School), and Tim Mathiason (The Langley School). Correspondence should be addressed to E. B. Lehman, Department of Psychology (MSN 3F5), 4400 University Dr., Fairfax, VA 22030 (e-mail: elehman@gmu.edu).

-Accepted by previous editor, Geoffrey R. Loftus
Considerable research with young adults indicates that they are able to minimize interference from the to-beforgotten material (see MacLeod, 1975, for a review) and that three major mechanisms are involved: selective rehearsal (Bjork, 1972), selective search (Epstein, 1972), and retrieval inhibition (Bjork, 1989; Geiselman \& Bagheri, 1985; Geiselman, Bjork, \& Fishman, 1983). In selective rehearsal, after the $F$ cue is presented, subjects devote all further rehearsal and other mnemonic activities to the R-cued items. In selective search, when given a cue to forget, subjects limit their memory search to Rcued items. In retrieval inhibition, the $F$ cue inhibits or blocks retrieval of F-cued items, essentially making them inaccessible. Furthermore, Bjork (1989) has proposed that, for all three of these mechanisms, some kind of list or item differentiation is a precondition. That is, before individuals can selectively rehearse or selectively search only the R-cued words or selectively suppress the F-cued words, they must have grouped the items into those that have been R-cued and those that have been F-cued.

A much smaller body of work with children indicates that they can first make use of an explicit instruction to forget in the elementary school years: 11 years of age with list cuing (Bray, Justice, \& Zahm, 1983; Posnansky, 1976, Experiment 2), and Grades 1, 2, and 3 with item cuing (Foster \& Gavelek, 1983; Lehman \& Bovasso, 1993; Posnansky, 1976, Experiment 1). The research also reveals that selective rehearsal is a major mechanism involved in age changes in children's control of their forgetting (Bray, Hersh, \& Turner, 1985; Bray et al., 1983; Foster \& Gavelek, 1983; Lehman \& Bovasso, 1993), is equivocal on re- 
trieval inhibition (Harnishfeger \& Pope, 1996; Lehman \& Bovasso, 1993; Lehman, McKinley-Pace, Wilson, Slavsky, \& Woodson, 1997), says little about selective search (Posnansky, 1976), and says nothing about item or list differentiation.

The present research focuses on item differentiationthat is, the partitioning of the items into remember and forget categories. Surprisingly, despite its prominence in theoretical discussions of how intentional forgetting is accomplished (e.g., Bjork, 1972, 1989; Epstein, 1972), little empirical work on this mechanism exists. There are a few studies in which adults have been asked to identify the cue that originally appeared with each item (Horton \& Petruk, 1980; MacLeod, 1975; Woodward \& Bjork, 1971). These studies show that young adults have a respectable, but far from perfect, ability to make cue judgments, although such judgments have typically been required on only a subset of the total number of items. The methodology has not been applied to children. Its use with children would tell us whether their difficulties on intentional forgetting tasks stem, at least in part, from their failure to adequately encode information about whether an item should be remembered or forgotten.

The developmental question is important because of its implications for conclusions about other mechanisms. For example, Harnishfeger and Pope (1996) noted that there are two possible interpretations of their finding that children in elementary school had difficulty withholding the production of to-be-forgotten items when they were asked to recall only to-be-remembered items in an intentional forgetting paradigm. First, children are less efficient at suppressing the production of to-be-forgotten words, and, second, children are less able to determine whether a word available for recall belongs to the to-beforgotten or to the to-be-remembered group. On the basis of studies demonstrating the early development of external source monitoring (e.g., Lindsay, Johnson, \& Kwon, 1991), Harnishfeger and Pope favored the inefficient inhibition interpretation. However, given the fact that memory for cues is not perfect for adults (e.g., Horton \& Petruk, 1980), a more direct study of cue memory in children seems warranted.

Three theoretical questions about cue memory were also of interest. First, what is the basis on which children make cue judgments? In the adult literature, it has been proposed that memory strength is used as the dimension for inferring cue (Horton \& Petruk, 1980; MacLeod, 1975). The proposal is supported by the finding that cue judgments are above chance only for items that have been recognized (MacLeod, 1975). Second, what role do cue judgments play in limiting interference from F-cued items in recall and recognition? MacLeod drew the strong conclusion that cue information is "not used directly for selective search" (p. 279). Adults do not first consciously identify the cue associated with each item in order to reduce interference from the F-cued items (Bjork, 1989). Third, what determines how well $R$ and $F$ cues are encoded? MacLeod suggested that the selective rehearsal of R-cued items is involved.

Three developmental studies are presented in which a selective grouping mechanism was investigated by (1) testing memory for the $R$ cue and $F$ cue presented with each item and (2) assessing the likelihood that item recall was organized by $\mathrm{R}$ and $\mathrm{F}$ cues. An item cuing procedure was employed. What varied across studies was the age group comparison (Grade 2 to college), the amount of differentiation between R-cued and F-cued items (unrelated vs. categorized lists), and the cue judgment test itself(recall items, recognize items, recall cues vs. recall cues only).

\section{EXPERIMENT 1}

The purpose of Experiment 1 was to chart the development of item tagging. Of interest was whether children encode information about memory cue (i.e., $R$ or $F$ ) along with the items, and, if they do, whether they use this information to organize recall of the items. Given evidence that memories of events often contain associated attributes, such as origin, frequency, and modality (Foley \& Johnson, 1985; Hasher \& Zacks, 1984; Lehman, Mikesell, \& Doherty, 1985), it was expected that information about cue would also be part of the memory for an event.

\section{Method}

Subjects. Twenty children in each of Grades 2, 4, and 6 of a parochial school serving middle-class families and 20 college students at a state university participated in the experiment. Approximately half of the subjects were boys and half were girls in each group. Mean ages in years were 8.2, 10.2, 12.3, and 20.8.

Materials. The stimuli consisted of 66 black line drawings of everyday objects (e.g., lamp, plane, tree, etc.) from the Peabody Picture Vocabulary Test-Revised (Dunn \& Dunn, 1981). They were selected to be not particularly categorizable. Each picture was centered on a $4 \times 6$ in. $(10.2 \times 15.2 \mathrm{~cm})$ white index card. Six were used for practice, 36 were presented during the initial study period, and 24 were used as "new" items during the final recognition test. Also on individual index cards were a brightly colored honey pot, a large red X, a bird, and a bee hive.

Two study lists were prepared. Picture order was the same on both. The first list was constructed so that $R$ and $F$ cues were randomly assigned to the study pictures, with the provision that no more than two cues of the same type appeared in succession. On the second list, the cues assigned to the pictures were the reverse of those on the first. Age groups were balanced with respect to study lists.

Procedure. A modification of Bjork's (1972) intentional forgetting paradigm that was designed to be of interest to children was used (see Lehman \& Bovasso, 1993). In this procedure, the children were told a story about a bee that needed to find honey to save its hive, and the children are invited to help the bee remember places where it found honey and to forget places where it did not find honey. Each "place" (i.e., the pictures) was presented for $5 \mathrm{sec}$, followed by either a honey pot (indicating that this place should be remembered) or a red $\mathrm{X}$ (indicating that it should be forgotten) for $5 \mathrm{sec}$. A blank card then appeared. The subjects indicated when they were ready to see the next picture. To keep the task age-appropriate, college students were not told the children's 
story. They were simply asked to remember the pictures that were followed by a green circle and to forget the pictures that were followed by a red X (i.e., the standard procedure for adults). The instruction to remember some pictures and forget others was emphasized during the two practice trials by having the subjects recall only the R-cued pictures.

After all the pictures on the test trial had been viewed, the subjects counted backwards for $1 \mathrm{~min}$ to interfere with rehearsal (by 1 from 200 for children, by 3 from 500 for adults). They were then asked to recall all of the pictures (regardless of cue). A recognition test of all 36 "old" pictures plus 24 "new" ones followed. During this test, the subjects also indicated whether an R cue or an F cue had followed each picture recognized as "old."

\section{Results}

Picture recall. Table 1 presents the proportions of $\mathrm{R}$ and F-cued pictures recalled by each age group. A 4 (grade) $\times 2$ (cue) analysis of variance (ANOVA) produced a significant effect of both grade and cue $[F(3,76)=$ $45.05, p<.01$, and $F(1,76)=177.59, p<.01$, respectively] and a significant interaction between grade and cue $[F(3,76)=11.04, p<.01]$. The interaction reflects two findings. First, an intentional forgetting effect (i.e., number of R-cued pictures recalled minus number of F-cued pictures recalled; see MacLeod, 1975) occurred for all age groups $(M \mathrm{~s}=.17, .23, .23$, and .49 , for Grades 2, 4, 6 and college students, respectively) [smallest $F(1,76)=15.72, p<.01]$. Second, the major age change occurred between Grade 6 and college. All three child groups differed from the college students (NewmanKeuls $p<.01$ ).

Picture recognition. The proportions of $\mathrm{R}$ - and $\mathrm{F}$-cued pictures recognized (i.e., hits; e.g., R-cued pictures labeled "old") appear in Table 1. The main effects of grade and cue were significant in a 4 (grade) $\times 2$ (cue) ANOVA $[F(3,76)=7.20, p<.01$, and $F(1,76)=65.70, p<.01$, respectively]. At all grades, R-cued pictures were recognized better than F-cued pictures, and second graders recognized fewer "old" pictures than did the other age groups (Newman-Keuls $p<.05$ ). False-alarm rates (proportion of "new" pictures judged "old") were low (Grade 2, .002 ; Grade 4, .011; Grade 6, .025; college, .011); in all

Table 1

Mean Proportions Correct in Experiment 1

\begin{tabular}{|c|c|c|c|c|c|}
\hline \multirow[b]{2}{*}{ Cue } & \multicolumn{3}{|c|}{ Grade } & \multirow[b]{2}{*}{ College } & \multirow[b]{2}{*}{$M$} \\
\hline & 2 & 4 & 6 & & \\
\hline \multicolumn{6}{|c|}{ Picture Recall } \\
\hline Remember & .27 & .38 & .39 & .71 & .44 \\
\hline Forget & .10 & .15 & .16 & .22 & .16 \\
\hline$M$ & .18 & .26 & .27 & .46 & \\
\hline \multicolumn{6}{|c|}{ Picture Recognition } \\
\hline Remember & .81 & .91 & .90 & .98 & .90 \\
\hline Forget & .72 & .76 & .84 & .83 & .79 \\
\hline$M$ & .77 & .84 & .87 & .90 & \\
\hline \multicolumn{6}{|c|}{ Conditionalized Cue Recall } \\
\hline Remember & .63 & .70 & .78 & .89 & .75 \\
\hline Forget & .76 & .77 & .73 & .85 & .78 \\
\hline$M$ & .69 & .73 & .75 & .87 & \\
\hline
\end{tabular}

Note $-n=20$ in each age group cases, the bias was to report that the picture had been Fcued.

Cue recall. The proportions of cues correctly recalled appear in Table 1. They have been conditionalized on picture recognition because of the grade and cue effects on the recognition scores described above. For example, cue memory for R-cued pictures was calculated by dividing the number of times the subject said "old/remember" to R-cued pictures by the number of R-cued pictures that had been correctly recognized as "old."

A 4 (grade) $\times 2$ (cue) ANOVA on the cue judgments produced a significant effect of grade $[F(3,76)=9.94, p<$ $.01]$ and a significant interaction between grade and cue $[F(3,76)=2.79, p<.05]$. The grade effect was significant for R-cued pictures $[F(3,76)=9.96, p<.01]$, but not for F-cued pictures. College students more accurately recalled $R$ cues than did the children's groups; six th graders' cue recall was higher than cue recall for second graders (Newman-Keuls $p<.05$ ). Even second graders, however, performed above chance (i.e., .50) $[t(19)=3.81$, $p<.01]$.

Relationship between cue recall and picture recall. The finding of greater recall of $F$ cues than of $\mathrm{R}$ cues seen in Table 1 for the second graders $[F(1,76)=6.16, p<$ $.05]$ is most likely to be attributable to the combination of lower recognition accuracy (described above) and the bias to report that a picture had been F-cued. Figure 1 indicates that, in all age groups, this bias occurred only for pictures that had not previously been recalled. A 4 (grade) $\times 2$ (cue) ANOVA on the cue recall proportions for unrecalled pictures produced significant main effects of grade $[F(3,76)=8.52, p<.01]$ and cue $[F(1,76)=$ $20.91, p<.01]$. Although the figure suggests that the bias was stronger for the younger two age groups, the effect was not reliable in the above ANOVA $[F(3,76)=$ $2.47, p<.07]$.

An R-cue bias also was present. If a picture had been recalled, the probability of its being labeled an $R$-cued item at recognition was greater than its probability of being labeled an F-cued item. A 4 (grade) $\times 2$ (cue) ANOVA on the cue recall proportions for recalled pictures indicated that the bias was about the same size in all age groups. Only the main effect of cue was significant $[F(1,71)=32.10, p<.01]$. Note that the degrees of freedom are somewhat lower here because the subjects who did not recall any F-cued pictures were eliminated from the analysis.

Because of interest in the basis on which children make cue judgments, it was also important to know whether cue recall was above chance only for pictures that had previously been recalled. For recalled pictures, the means were $.70, .77, .70$, and .83 for Grade 2 , Grade 4 , Grade 6, and college subjects, respectively. For notrecalled pictures, the means were $.65, .69, .71$, and .84 , respectively. The closest to chance (i.e., .50) was Grade 2 for pictures not recalled $[t(19)=6.77, p<.01]$. Thus, cue recall was above chance for both recalled and notrecalled pictures. 


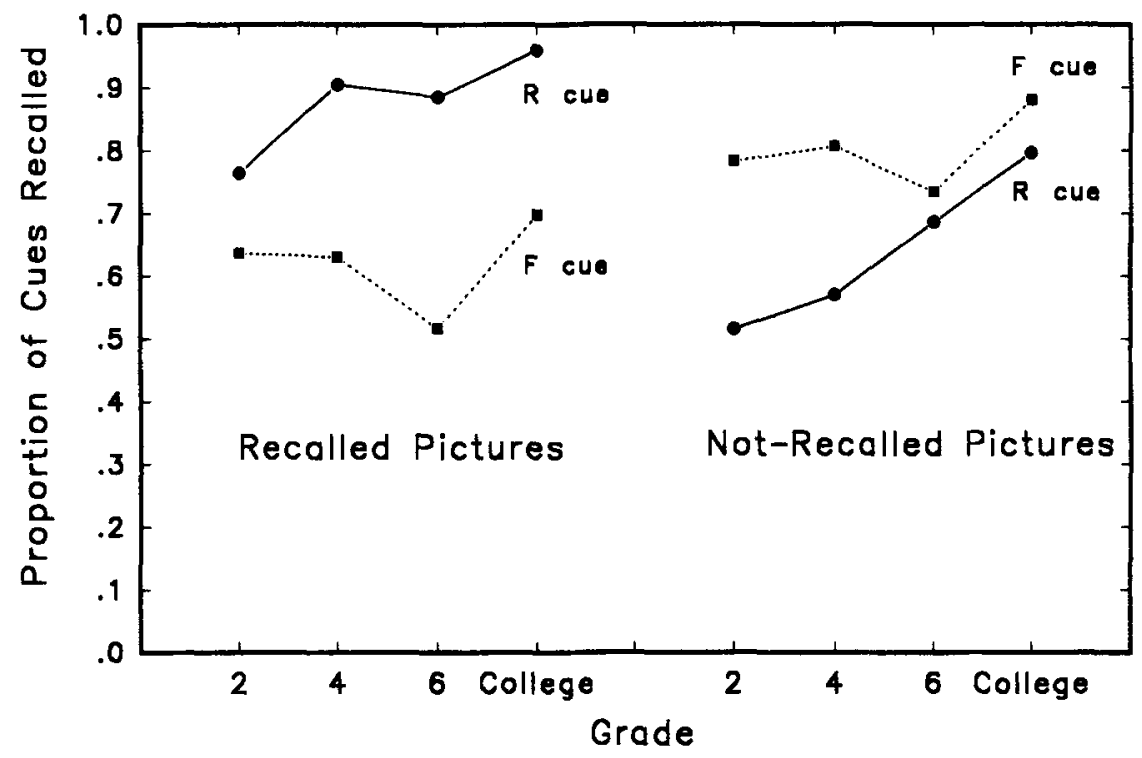

Figure 1. Proportion of cues recalled for recalled and not-recalled pictures as a function of age in Experiment 1.

Recall clustering by cue. Clustering scores were derived by the method used by Frankel and Cole (1971), chosen because it is sensitive to the total number of items recalled and to the number of items recalled from each category. With this method, clustering is expressed as a $z$ score based on a comparison of the number of runs expected by chance and the number actually observed. A score of zero indicates no clustering; the higher the negative score, the greater the amount of clustering.

The mean $z$ scores were $+0.06,-0.47,-0.54$, and -1.75 for Grade 2, Grade 4, Grade 6 , and college subjects, respectively. The effect of grade was significant in a one-way ANOVA $[F(3,76)=10.00, p<.01]$, with college students organizing their recall by cue more than the children did (Newman-Keuls $p<.01$ ). Only the clustering scores of the adults differed significantly from zero (i.e., a $z$ score $>-1.64$ ).

\section{Discussion}

The results corroborated the finding in previous research that, with item cuing, children as young as second graders recall and recognize more $\mathrm{R}$-cued pictures than F-cued pictures (e.g., Lehman \& Bovasso, 1993). In the earlier work, the intentional forgetting effect increased with age in children; however, in the present experiment, the major developmental change was between the children and the adults. The results thus support Bray et al.'s (1983) conclusion that important changes in the ability to eliminate interference from irrelevant information in memory occur during adolescence.

The present experiment also corroborated the conclusion from adult studies that information about memory cue is stored as part of the representation for items encoded in memory (e.g., MacLeod, 1975). What it adds is the finding that children as young as second graders also encode the $\mathrm{R}$ or the $\mathrm{F}$ cue associated with each picture, although to a lesser extent than do college students. It also shows that, while information about cue is part of the memory for an event, this distinction is not adequately used as the basis for clustering in recall by children. Taken together, these results suggest that children's difficulties on intentional forgetting tasks stem, at least in part, from their poorer encoding and use of information about whether an item should be remembered or forgotten.

\section{EXPERIMENT 2}

Experiment 2 had two purposes. First, we included a group of adolescents in order to explore the large improvement in cue recall found in Experiment 1 between sixth graders and college students. Second, we attempted to reduce the potential for confusion between $R$ and $F$ cues by altering the list of presentation pictures for some of the children so that $R$ and $F$ cues were associated with particular taxonomic categories.

A group of children and a group of adolescents were asked to remember all the items from some taxonomic categories and to forget all the items from other taxonomic categories in an item cuing procedure. Additional groups of the same two ages were given the standard procedure from Experiment 1. Adult work has shown that cue recall is higher when cue type is consistent with taxonomic category (Horton \& Petruk, 1980; Woodward \& Bjork, 1971, Experiment 2). No change in the size of the intentional forgetting effect was expected, however, since the Horton and Petruk and the Woodward and Bjork studies with college students as well as one with third and seventh graders that compared the intentional forgetting effect for category consistent and noncatego- 
rized words (Posnansky, 1976, Experiment 1) found that the category manipulation had little impact on the magnitude of the intentional forgetting effect.

\section{Method}

Subjects. Twenty-two children in Grade 3 and 8 children in Grade 4 ( $M$ age $=9.6$ years) and 2 adolescents in Grade 8 and 21 adolescents in Grade 9 ( $M$ age $=15.0$ years $)$ participated in the experiment. Most were attending either a parochial elementary school or a parochial high school serving middle-class families in the suburbs of a large metropolitan area ( 3 were neighbors of the researchers enlisted when all children at the schools with parental approval had been tested). Fourteen children and 11 adolescents were randomly assigned to the standard presentation condition. Sixteen children and 12 adolescents were randomly assigned to the categorized presentation condition. Approximately half of the subjects were boys and half were girls in each age $\times$ condition group; the groups were approximately balanced with respect to the two study lists (i.e., $R$ cue first or $F$ cue first).

Materials. The stimuli for the standard presentation condition were identical to those described in Experiment 1. The same procedure was used to prepare the stimuli for the categorized presentation condition. The categorized study lists consisted of pictures of 6 objects from each of 6 taxonomic categories (i.e., toys, animals, vehicles, tools, household objects, and food). Members of a taxonomic category were randomly distributed throughout the lists. For the first categorized list, objects in 3 of the categories were all assigned $R$ cues; the others were assigned $F$ cues. The cues were reversed for the second categorized list. No more than two cues of the same type appeared in succession. Twenty-four new pictures were added for the final recognition test. Eight were objects from the original categories, and 16 were objects from other categories.

Procedure. Study and test procedures were identical to those in Experiment 1 . The subjects were asked to remember the pictures followed by $R$ cues and to forget the pictures followed by $F$ cues. They were informed that they would be required to later recall the $\mathrm{R}$-cued pictures, however, no information was given about the taxonomic category manipulation.

\section{Results}

Picture recall. Table 2 presents the proportions of Rand F-cued pictures recalled by each age group. A 2 (grade) $\times 2$ (presentation) $\times 2$ (cue) ANOVA produced three significant main effects: More pictures were recalled by adolescents than by children $[F(1,49)=17.31$, $p<.01]$, in the categorized presentation than in the standard presentation $[F(1,49)=7.45, p<.01]$, and when followed by $\mathrm{R}$ cues than when followed by $\mathrm{F}$ cues $[F(1,49)=$ $142.59, p<.01]$. The interaction between age and cue, which is usually found when college students are included, did not occur in this experiment, where the comparison was primarily between third and ninth graders. Thus, the intentional forgetting effect in recall was not reliably larger for the adolescents than for the children.

Picture recognition. The proportions of pictures correctly recognized as "old" appear in Table 2 . A 2 (grade) $\times 2$ (presentation condition) $\times 2$ (cue) ANOVA on the picture recognition scores produced a significant main effect of cue $[F(1,49)=68.88, p<.01]$ and a significant interaction between grade and cue $[F(1,49)=5.92, p<$ $.05]$. The intentional forgetting effect in picture recognition was greater for the adolescents than for the children $(M \mathrm{~s}=.20$ and .11 , respectively) $[t(51)=-2.45, p<.05]$. False-alarm rates were low (children, .006 ; adolescents, .027 ), and the bias to report that a picture had been Fcued was $100 \%$ for children and $73.3 \%$ for adolescents.

Cue recall. As in Experiment 1, the proportions of cues correctly recalled were conditionalized on picture recognition (see Table 2). When a 2 (grade) $\times 2$ (presentation condition) $\times 2$ (cue) ANOVA was performed on these proportions, only the interaction between grade and cue was significant $[F(1,49)=16.15, p<.01]$. The children were more accurate in recalling $\mathrm{F}$ cues than in recalling $\mathrm{R}$ cues $[F(1,49)=14.99, p<.01]$, and the increase with age in memory for $\mathrm{R}$ cues was significant $[F(1,49)=6.10, p<.05]$, as was the decrease with age in memory for $\mathrm{F}$ cues $[F(1,49)=4.73, p<.05]$. Neither the main effect of taxonomic category nor any interactions with it were reliable.

Relationship between cue recall and picture recall. As in Experiment 1, the children's better recall of $F$ cues was most likely due to their stronger bias to report that a pic-

Table 2

Mean Proportions Correct in Experiment 2

\begin{tabular}{|c|c|c|c|c|c|}
\hline \multirow[b]{2}{*}{ Cue } & \multicolumn{2}{|c|}{ Standard Presentation } & \multicolumn{2}{|c|}{ Categorized Presentation } & \multirow[b]{2}{*}{$M$} \\
\hline & Grades 3 and 4 & Grades 8 and 9 & Grades 3 and 4 & Grades 8 and 9 & \\
\hline \multicolumn{6}{|c|}{ Picture Recall } \\
\hline Remember & .36 & .47 & .41 & .56 & .44 \\
\hline Forget & .10 & .14 & .14 & .19 & .14 \\
\hline$M$ & .23 & .30 & .27 & .38 & \\
\hline \multicolumn{6}{|c|}{ Picture Recognition } \\
\hline Remember & .89 & .95 & .89 & .94 & .91 \\
\hline Forget & .76 & .72 & .79 & .76 & .76 \\
\hline$M$ & .82 & .84 & .84 & .85 & \\
\hline \multicolumn{6}{|c|}{ Conditionalized Cue Recall } \\
\hline Remember & .69 & .79 & .74 & .85 & .76 \\
\hline Forget & .85 & .70 & .85 & .81 & .81 \\
\hline$M$ & .77 & .75 & .80 & .83 & \\
\hline
\end{tabular}

Note- $-n s=30$ children in Grades 3 and 4 , and 23 adolescents in Grades 8 and 9 . 


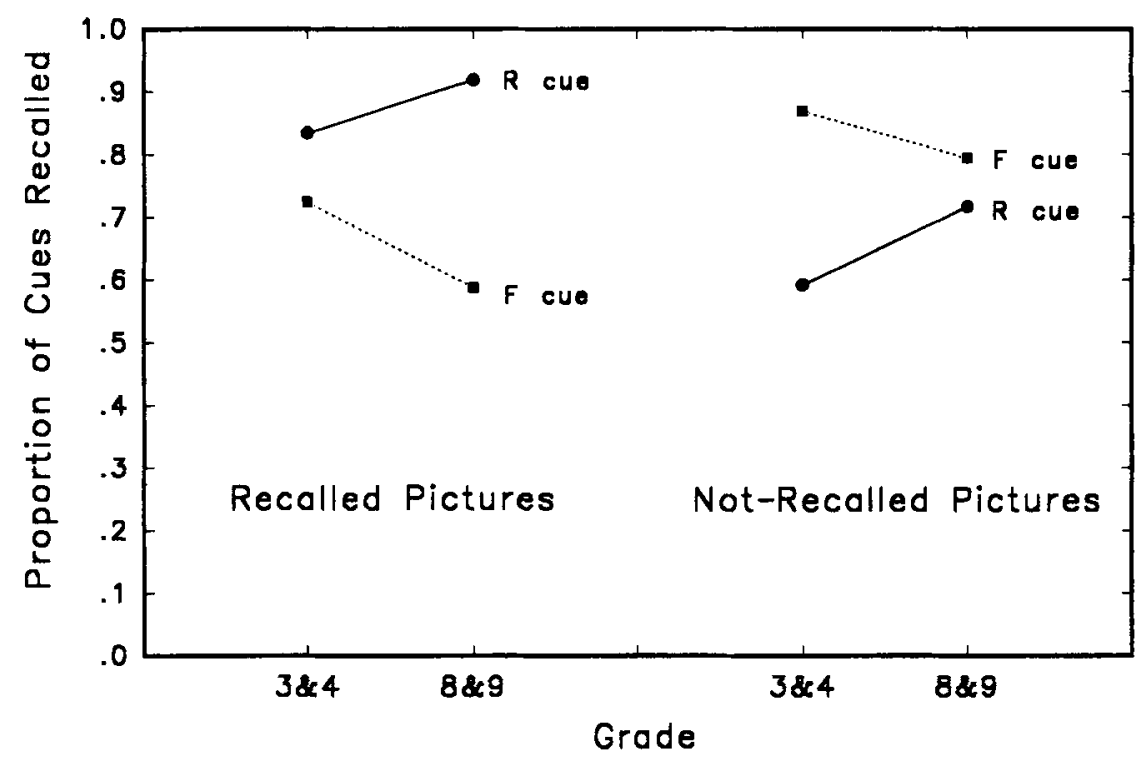

Figure 2. Proportion of cues recalled for recalled and not-recalled pictures as a function of age in Experiment 2.

ture had been F-cued. In both age groups, this bias occurred only for pictures that had not previously been recalled (see Figure 2). A 2 (grade) $\times 2$ (cue) ANOVA on the cue recall proportions for unrecalled pictures produced a significant main effect of cue $[F(1,51)=34.90$, $p<.01]$ and a significant interaction between grade and cue $[F(1,51)=11.11, p<.01]$. The $\mathrm{F}$-cue bias for unrecalled pictures was significant for children $[F(1,51)=$ $43.37, p<.01]$, but not for adolescents $[F(1,51)=3.35$, $.05<p<.10]$.

An R-cue bias for recalled pictures again appeared for both age groups (see Figure 2). In a 2 (grade) $\times 2$ (cue) ANOVA on the cue recall proportions for recalled pictures, only the main effect of cue was significant $[F(1,45)=$ $11.01, p<.01]$. Also as occurred in Experiment 1, cue recall was above chance both for pictures that had previously been recalled and for pictures that had not [smallest $t(29)=9.62, p<.01]$. The cue recall means for recalled pictures were .78 for children and .75 for adolescents. The means for not-recalled pictures were .73 and .76 , respectively.

Recall clustering by cue. The mean Frankel and Cole (1971) $z$ scores for clustering recall by $R$ and $F$ cues were -0.07 for children and -1.03 for adolescents in the standard presentation condition and -0.94 for children and -1.07 for adolescents in the categorized presentation condition. None of these $z$ scores differed significantly from 0 , and a 2 (grade) $\times 2$ (presentation condition) ANOVA on the $z$ scores produced neither main effects nor interaction effects.

\section{Discussion}

The standard condition in Experiment 2 replicated a number of the findings from Experiment 1, among them the size of the intentional forgetting effect in both recall and recognition for children and the age changes in cue recall and biases. A comparison of the two experiments also indicated that, although the ninth graders in Experiment 2 produced a somewhat larger intentional forgetting effect and showed somewhat more clustering of recall by cue than did the sixth graders in Experiment 1, there was no improvement across these ages in cue recall. Furthermore, all scores for the adolescents were considerably lower than those of college students. These results indicate that changes in the ability to encode and use information about memory cue are still occurring in adolescence.

The attempt to increase the differentiation between $R$ and $\mathrm{F}$ cues by associating them with items from different categories was not successful. As expected, on the basis of previous research with children and adults (e.g., Horton \& Petruk, 1980), the size of the intentional forgetting effect was similar across categorization conditions. Unexpected was the finding that cue recall, although in the predicted direction, was not reliably higher when cue type was consistent with taxonomic category. Unfortunately, since college students were not included in the design of this experiment, it is impossible to know if the different results across experiments are attributable to the age group tested. It may be, for example, that the enhancement in cue recall with a categorized presentation occurs only for young adults. Alternatively, methodological differences between experiments might be responsible for the results. For example, in the present experiment, cue recall was required for a large proportion of the items (i.e., all items recognized). In the adult studies, cue recall was only required for a small subset of items - those recalled (Woodward \& Bjork, 1971) or 24 
randomly selected words from the 72 words presented (Horton \& Petruk, 1980). Furthermore, in the present experiment, the subjects were not informed about the taxonomic relationships among the pictures, whereas in some of the adult work, they were (e.g., Woodward \& Bjork, 1971). These methodological differences deserve further work.

\section{EXPERIMENT 3}

Experiment 3 had two purposes. First, we sought to determine whether cue recall in the first two experiments had been affected by the requirement to recall and recognize pictures first. In Experiment 3, the subjects were asked to recall only the cue associated with each picture. Second, we added confidence judgments to the task in order to investigate differences in confidence as a function of age and cue.

\section{Method}

Subjects. Twelve children in Grades 2, 3, and 4 and 12 college students from the sources described above participated in the experiment. Mean ages were 9.4 and 19.0 years, respectively. Half of the subjects in each age group received the R-cue-first study list. The other half received the F-cue-first study list.

The sample of children included those in Grades 2, 3, and 4 ( $n s=2,5$, and 5, respectively), because the results of Experiment 1 indicated that decision making about cues at these grade levels was similar (i.e., in terms of biases). Nevertheless, analyses for Experiment 3 were also done with the two second graders removed. Results were the same as those done on the entire sample.

Materials and Procedure. Study lists and procedures were identical to those in Experiment 1. In the testing phase of Experiment 3 , however, the subjects were shown only the 36 pictures that had originally been presented, and they were asked to recall the cue associated with each picture and to give an estimate of their confidence in each cue judgment on a 3-point scale (very sure, sort of sure, just a guess). For the children, black line drawings of schematic faces were always in view to help them remember the scale. The faces were identical except for the mouth (full smile, half smile, and no smile). After judgments about cue had been made for all pictures, the subjects were asked to describe in words how they had decided whether a picture had been R-cued or Fcued.

\section{Results}

Cue recall. As can be seen in Table 3, there was no interaction between age and cue on cue recall in Experiment 3 , as there had been in the first two experiments. In a 2 (grade) $\times 2$ (cue) ANOVA, only the main effect of age, with the adults correctly recalling more cues than the children, was significant $[F(1,22)=6.58, p<.05]$. Cue recall, however, was above chance for both the children and the adults.

When the subjects were asked how they had decided which cue was associated with a particular picture, about $80 \%$ of the children and all adults verbally stated the following rule: "If a picture looks familiar, say R cue; if it doesn't, say $F$ cue." Thus, both the children and the adults used the same decision strategy to decide whether a picture had been R-cued or F-cued.
Table 3

\begin{tabular}{lccc}
\multicolumn{4}{c}{ Mean Proportions Correct in Experiment 3 } \\
\hline \multicolumn{3}{c}{ Grades } & \\
& 2,3 , and 4 & College & $M$ \\
Remember & Cue Recall & \\
Forget & .74 & .85 & .79 \\
$M$ & .78 & .93 & .86 \\
& .76 & .89 & \\
Remember & Confidence Judgments* & \\
Forget & .66 & .85 & .76 \\
$M$ & .51 & .56 & .54 \\
\hline
\end{tabular}

Note $-n=12$ in each age group. *Proportion of cue judgments for which subjects were "very sure."

Confidence judgments. Table 3 shows the proportion of cue recall for which the children and the adults were highly confident about their cue choice (e.g., the number of cues given to R-cued pictures where the person was "very sure" of his/her answer divided by the total number of R-cued pictures-i.e., 18). A 2 (grade) $\times 2$ (cue) ANOVA indicated that only the main effect of cue was significant $[F(1,22)=30.12, p<.01]$. All subjects were more confident about their R-cue judgments than they were about their F-cue judgments.

The difference between R-and F-cue confidence was especially large when the cue recall was correct. A 2 (grade) $\times 2$ (cue) $\times 2$ (correct/incorrect cue recall) ANOVA on the proportions of "very sure" about cue recall ratings produced significant main effects of cue $[F(1,22)=$ $14.63, p<.01]$ and correct/incorrect $[F(1,22)=55.72, p<$ $.01]$, as well as an interaction between cue and correct/ incorrect $[F(1,22)=4.27, p=.05]$. The children and the adults were more confident about their $\mathrm{R}$-cue recall than they were about their F-cue recall when their cue recall was correct $(M \mathrm{~s}=.84$ and .54 , respectively) $[F(1,22)=$ $8.07, p<.01]$. The difference in confidence when cue recall was incorrect was not significant $(M \mathrm{~s}=.41$ and .34$)$ $(F<1)$.

\section{Discussion}

Eliminating picture recall and recognition had minimal effects on the magnitude of cue judgments. As in Experiments 1 and 2, the early-elementary-school-aged children recalled about $75 \%$ of the cues. The young adults recalled almost $90 \%$ of the cues.

On the other hand, when picture recall and recognition were not part of the procedure, the interaction between age and cue on cue recall did not occur. This result is further evidence that the younger children's better recall of $F$ cues than of $R$ cues is an artifact of the methodology and is not attributable to some process difference between younger and older children. In Experiments 1 and 2, the subjects could choose either "F cue" or "new" for pictures that did not look familiar. The young children in these two experiments were more likely to report that an unfamiliar picture had been followed by an $F$ cue than were the older children and adults. In Experiment 1, 
they also had lower recognition scores. Thus, their accuracy for the $F$ cue was artificially boosted, and a cue $x$ age interaction on cue recall was produced.

\section{GENERAL CONCLUSIONS}

This group of experiments makes available for the first time information about the accuracy of children's cue judgments in intentional forgetting. They demonstrate that information about memory cue is stored as part of the representation for items encoded in memory by children as young as second graders and that the major improvement with age in overall cue recall and in organizing picture recall by cue occurs during adolescence.

These results with the very direct cue judgment technique suggest that item differentiation is related to intentional forgetting. At the very least, the results indicate that item differentiation cannot be dismissed in attempts to account for age changes in intentional forgetting on the basis of findings from the external source monitoring literature, as Harnishfeger and Pope (1996) have done. The present experiments make it clear that children are less able to determine whether an item available in memory belongs to the to-be-remembered group or the to-beforgotten group than are adults.

What is less clear is the exact role that item differentiation plays in intentional forgetting. Is it a precondition for selective rehearsal, selective search, and retrieval inhibition, as Bjork (1989) has proposed? The present group of experiments were not designed to answer this question. Nevertheless, in their answers to the three theoretical questions from the adult literature described in the introduction, the experiments provide some suggestions about the nature of item differentiation in both children and young adults.

The first question has to do with the basis on which cue judgments are made. Although the "picture familiarsay yes/picture unfamiliar-say no" decision rule used by the subjects in Experiment 3 suggests that memory strength may be the dimension from which cue type is inferred, as has been proposed in the adult literature by Horton and Petruk (1980) and MacLeod (1975), observations from the present experiments lead to a modification of this proposal. First, although, the subjects verbally reported use of the above strategy at the end of Experiment 3, many of the cue judgments across all three experiments were made almost instantaneously, with little indication of a conscious application of the strategy. Second, although MacLeod found that cue judgments were above chance only for items that had been recognized, in the present research cue information was retrievable both for items recalled and for those that had not been recalled. It is not known exactly why these differences in results have occurred, although the assessment procedures varied considerably between studies. Nevertheless, our results suggest that a conscious attempt to use memory strength as a dimension for inferring cue is more likely to be used in situations where cue type does not immediately come to mind.

The second question asks what role cue judgments play in limiting interference from F-cued items in recall and recognition. We are in agreement with Bjork (1989) that subjects do not first consciously identify the cue associated with each item in order to reduce interference from the F-cued items. On the other hand, MacLeod's (1975) conclusion that cue information is "not used directly for selective search" (p. 279) seems too strongly worded. It is not unusual for subjects in intentional forgetting studies, both children and adults, to begin recalling items with the statement, "Let me give you the remember words first." After recalling some words, they say, "Now here are forget words." These subjects are certainly making use of $R$ and $F$ cues to organize recall. Thus, it appears that the strategy is present. The problem is that subjects are not always able to accurately recall the cues.

The third question is concerned with factors that determine how well $R$ and $F$ cues are encoded. The developmental literature provides support for MacLeod's (1975) proposal that $R$ and $F$ cues are encoded along with the items as a consequence of the selective rehearsal of $\mathrm{R}$ items. In fact, since older children and adults limit their rehearsal to R-cued words more exclusively than do young children (Lehman \& Bovasso, 1993), they would be expected to have encoded more accurate information about memory cues. Furthermore, these cues are then available for organizing items in recall. Given what is known about children's strategy production, mediation, and utilization deficiencies (e.g., Miller \& Seier, 1994), whether and to what extent subjects use the cues in recall is also expected to be a function of age.

Taken together, the results of the present experiments support proposals that identify item differentiation as an important mechanism in children and adult's intentional forgetting. They also emphasize the need for further work on this least researched intentional forgetting mechanism.

\section{REFERENCES}

BJoRK, R. A. (1972). Theoretical implications of directed forgetting. In A. W. Melton \& E. Martin (Eds.), Coding processes in human memory (pp. 217-235). Washington, DC: Winston.

BJORK, R. A. (1989). Retrieval inhibition as an adaptive mechanism in human memory. In H. L. Roediger III \& F. I. M. Craik (Eds.), Varieties of memory and consciousness: Essays in honour of Endel Tulving (pp. 309-330). Hillsdale, NJ: Erlbaum.

Bray, N. W., Hersh, R. E., \& Turner, L. A. (1985). Selective remembering during adolescence. Developmental Psychology, 21, 290-294.

Bray, N. W., Justice, E. M., \& Zahm, D. N. (1983). Two developmental transitions in selective remembering strategies. Journal of $E x$ perimental Child Psychology, 36, 43-55.

Dunn, L. M., \& Dunn, L. M. (1981). Peabody Picture Vocabulary Test-Revised. Circle Pines, MN: American Guidance Service.

EPSTEIN, W. (1972). Mechanisms of directed forgetting. In G. H. Bower (Ed.), The psychology of learning and motivation (Vol. 6, pp. 147 191). New York: Academic Press.

Foley, M. A., \& Johnson. M. K. (1985). Confusions between memories for performed and imagined actions: A developmental comparison. Child Development, 56, 1145-1155. 
Foster, R. N., \& Gavelek, J. R. (1983). Development of intentional forgetting in normal and reading-delayed children. Journal of Educational Psychology, 75, 431-440.

Frankel, F., \& Cole, M. (1971). Measures of organization in free recall. Psychological Bulletin, 76, 39-44.

GeISELMAN, R. E., \& BaGHERI, B. (1985). Repetition effects in directed forgetting: Evidence for retrieval inhibition. Memory \& Cognition, $13,57-62$.

Geiselman, R. E., Bjork, R. A., \& Fishman, D. L. (1983). Disrupted retrieval in directed forgetting: A link with posthypnotic amnesia. Journal of Experimental Psychology: General, 112, 58-72.

HARNISHFEGER, K., \& POPE, R. S. (1996). Intending to forget: The development of cognitive inhibition in directed forgetting. Journal of Experimental Child Psychology, 62, 292-315.

HASHER, L., \& ZACKS, R. T. (1984). Automatic processing of fundamental information: The case of frequency of occurrence. American Psychologist, 39, 1372-1388.

HoRton, K. D., \& Petruk, R. (1980). Set differentiation and depth of processing in the directed forgetting paradigm. Journal of Experimental Psychology: Human Learning \& Memory, 6, 599-610.

Lehman, E. B., \& Bovasso, M. (1993). Development of intentional forgetting in children. In M. L. Howe \& R. Pasnak (Eds.), Emerging themes in cognitive development. Vol. I: Foundations (pp. 214-233) New York: Springer-Verlag.

Lehman, E. B., McKinley-Pace, M. J., Wilson, J. A., Slavsky, M. D.,
\& WoODson, M. E. (1997). Direct and indirect measures of intentional forgetting in children and adults: Evidence for retrieval inhibition and reinstatement. Journal of Experimental Child Psychology, 64, 295-316.

Lehman, E. B., Mikesell, J. W., \& Doherty, S. C. (1985). Long-term retention of information about presentation modality by children and adults. Memory \& Cognition, 13, 21-28.

Lindsay, D. S., Johnson, M. K., \& Kwon, P. (1991). Developmental changes in memory source monitoring. Journal of Experimental Child Psychology, 52, 297-318.

MACLEOD, C. M. (1975). Long-term recognition and recall following directed forgetting. Journal of Experimental Psychology: Human Learning \& Memory, 104, 271-279.

Miller, P. H., \& SeIER, W. L. (1994). Strategy utilization deficiencies in children: When, where, and why. In H. W. Reese (Ed.), Advances in child development and behavior (Vol. 25, pp. 107-156). New York: Academic Press.

PosNANSKY, C. J. (1976). Directed forgetting among third and seventh graders. Contemporary Educational Psychology, 1, 247-256.

Woodward, A. E., JR., \& BJORK, R. A. (1971). Forgetting and remembering in free recall: Intentional and unintentional. Journal of Experimental Psychology, 89, 109-116.

(Manuscript received March 15, 1996; revision accepted for publication June 27,1997 .) 